\title{
Negotiatores en la estructura social de las provincias romanas del Alto y Medio Danubio
}

\author{
M. ㄹa del Henar Gallego Franco*
}

Las provincias romanas de Rhaetia, Noricum y Pannonia ${ }^{1}$ se extienden a lo largo del alto y medio Danubio, constituyendo una de las principales fronteras del Imperio Romano en Europa, y englobando, en líneas generales, los actuales territorios de Baviera, en el sur de Alemania, Austria, la mitad occidental de Hungría y el norte de la antigua Yugoslavia. La noción imperial de limes, así como su caracterización, evolución, y peculiaridades que aporta a las provincias cuya existencia marca, ha sido objeto de constantes estudios críticos y revisiones historiográficas, en las que se impone sin duda la idea del limes, y de los grandes cursos fluviales que lo constituyen, como un elemento dinámico de comunicación e interacción cultural, más que como una línea rígida de separación que delimita y separa el territorio de dominio romano de los bárbaros libres ?

* Historia Antigua. Universidad de Valladolid.

1 Sobre la conquista y evolución de Rhaetia, Noricum y Pannonia, cfr., entre otras, J.P. MARTín, Les provinces romaines d'Europe centrale et occidentale, París, 1990, 20-24, 52-54, 81-86, 95-98, 134-135, 171-174; G. WINKLER, "Die Statthalter der römischen Provinz Raetien unter dem Principat», Bayerische Vorgeschichtsblätter, 36, 1971, 50 ss.; J. PRIEUR, “L'historie des régions alpestres sous le Haut-Empire romain", Aufstieg und Niedergang der römischen Welt, II, 5.2, 1976, 630-656; B. OVERBECK, «Raetien zur Prinzipatzeit», Aufstieg und Niedergang der römischen Welt, II, 5.2, 1976, 658-689; G. AlFóldy, Noricum, London, 1974; A. Mócsy, Pannonia and Upper Moesia, London, 1974; A. DoвO, Die Verwaltung der römischen Provinz Pannonien von Augustus bis Diocletianus, Budapest, 1968; J. FITZ, The great age of Pannonia (A.D. 193-284), Budapest, 1982; M.H. Gallego, Prosopografia, onomástica y sociedad en el Imperio Romano. Las estructuras sociales. Las provincias de Rhaetia, Noricum, Pannonia Superior e Inferior, Valladolid, 1995, 51-106 (en prensa).

2 Además de obras ya clásicas, E.N. LuTTwak, The Grand Strategy of the Roman Empire from the First Century A.D. to the Third, Baltimore, 1976, o F. MILLAR, The Roman Empire and its Neighbours, London, 1970, en esta línea de renovación de los estudios de frontera destacan especialmente los trabajos de C.R. WHITTAKER, "Trade and Frontiers of the Roman Empire" en P.D.A. GARNSEY/C.R. WHITTAKER, Trade and Famine in Classican Antiquity, Cambridge, 1983; Idem, 
En este sentido, la presencia del limes y la existencia de un curso fluvial de primer orden como es el Danubio, tuvo en efecto altamente estimulador de las actividades de intercambio en las provincias del alto y medio curso del río, objeto de este estudio ${ }^{3}$. Los Alpes centrales y el territorio que se extiende al norte, donde se asentarán luego las provincias romanas de Rhaetia y Noricum, atraen sin duda el interés romano, ya que la zona controlaba los accesos y puntos de paso de numerosas rutas de comercio de dirección norte-sur desde Italia, las que iban hacia Germania y Gallia (centro-oeste), y las que llegaban hasta las riveras del Danubio, donde se encontraban con las rutas que venian del mar Báltico, como la del ámbar. Al mismo tiempo, el comercio en la región danubiana alcanzó una importancia excepcional en todo el Imperio, ya que comprendía rutas hacia el Báltico, el Mar Negro y Rusia, e Italia. También tenía gran interés el comercio con los pueblos fronterizos, como los Marcomanos, Quados y Dacios, que era utilizado por Roma como un mecanismo de control sobre estas tribus ${ }^{4}$. Pannonia cuenta con otro importante factor para el desarrollo de la actividad comercial, como es la extraordinaria presencia de tropas en su territorio, que ofrecían un importante mercado cautivo con efectivo para gastar. De hecho, el abastecimiento de los ejércitos de la frontera tuvo que ser una cuestión de importancia capital para Roma, por lo que el Estado tutelaría de cerca, especialmente en los primeros tiempos del Imperio, el despegue económico de las regiones fronterizas, favoreciendo el desplazamiento a la zona de negotiatores e intermediarios a través de una política de exenciones fiscales ${ }^{5}$.

Les frontières de l'Empire romain, París, 1989; Idem, Frontiers of the Roman Empire. A Social and Economic Study, London, 1994; S.K. DRummond y L.H. Nelson, The Western Frontiers of Imperial Rome, New York, 1994.

3 Cfr., entre otras, M.P. Charlesworth, Trade routes and commerce of the Roman Empire, Chicago, 1976 (Ed. 1926); O. SCHLIPPSCHUH, Die Händler in römischen Kaiserreich in Gallien, Germanien und den donauprovinzen Raetien, Noricum und Pannonien, Amsterdam, 1974; J.H. D'ARMS, Commerce and Social Standing in Ancient Rome, Cambridge, 1981; G. WALSER, Die römischen Strassen und Meilensteine in Raetien, Stuttgart, 1983; P. GARNSEY/K. HOPKINS/C.R. WHITTAKER, Trade in the Ancient Economy, London, 1983; C.R. WHITTAKER, Les Frontières de I'Empire romain, París, 1989; Idem, Frontiers of the Roman Empire. A Social and Economic Study, London, 1994; S.K. Drummond/L.H. NELSON, The Western Frontiers of Imperial Rome, New York, 1994.

4 C.R. WhitTakeR, Les Frontières de l'Empire romain, París, 1989, 59-73; S.K. Drummond/ L.H. NELSON, The Western Frontiers of Imperial Rome, New York, 1994, 101-126.

5 A. Mócsy, Pannonia and Upper Moesia, Londres, 1974, 127-129; S.K. Drummond/L.H. NELSON, The Western Frontiers of Imperial Rome, New York, 1994, 91-96, 101-109, 127-132; C.R. WHITTAKER, Frontiers of the Roman Empire. A Social and Economic Study, London, 1994, 99-113, 118-120. 
Nuestro trabajo se fundamenta en una detallada búsqueda a través de las fuentes epigráficas ${ }^{6}$ de Rhaetia, Noricum y Pannonia que nos permite abordar un análisis de aquellos individuos que explicitan una profesión relacionada con los intercambios comerciales. Establecemos, en primer lugar, su caracterización onomástica en cada una de las provincias que nos interesan, para analizar luego sus peculiaridades socioeconómicas como grupo, y sus mecanismos de intervención y participación en el estorno social. Finalmente, pondremos de relieve las líneas claves de la distribución geográfica y cronológica de estos negotiatores en los territorios que nos interesan, así como las implicaciones que de ellas se desprenden.

Es un hecho altamente significativo el que sea precisamente la provincia de Rhaetia, la más modesta y con el menor volumen de testimonios epigráficos de las del Alto y Medio Danubio, la que nos brinde el mayor número de negotiatores, incluso sobrepasando a las dos Pannoniae. Las fuentes epigráficas confirman así el papel estratégico excepcional jugado por esta pequeña provincia en las rutas de comunicación del Imperio, siendo un nudo de enlace, como ya hemos señalado, con Italia, Gallia y Germania, así como con las provincias del Danubio y con la Germania libre ${ }^{7}$.

Desde el punto de vista onomástico, casi la totalidad de los negotiatores constatados en Rhaetia son ciudadanos romanos, predominando el tria nomina ${ }^{8}(70 \%)$ frente al duo nomina (30\%), más propio de una cronología más tardía, penetrando ya en el s. Ill. Entre sus nomina encontramos a tres de los grupos gentilicios más sólidamente representados en la provincia ${ }^{9}$,

\footnotetext{
6 Las abreviaturas de grandes corpora epigráficos que empleamos en el presente trabajo son: $\mathrm{CIL}=$ Corpus Inscriptionum Latinarum, vol. III y suppl; $\mathrm{AE}=$ Année Épigraphique, París, 1900-1990; ILI = A. \& J. SASEL, «Inscriptiones Latinae quae in luguslavia inter annos MCMXL et MCMLX repertae et editae sunt», Situla, V, 1563; Idem, «Inscriptiones Latinae quae in Iuguslavia inter annos MCMLX et MCMLXX repertae et editae sunt», Situla, XIX, 1978; Idem, "Inscriptiones latinae quae in luguslavia inter annos MCMII et MCMXL repertae et editae sunt", Situla, XXV, 1986.

7 Cfr. G. WALSER, Die römischen Strassen und Meilensteine in Raetien, Stuttgart, 1983.

8 En CIL III 5800 consideramos también portador de un tria nomina a P. Antonius, cuyo cognomen se omite en el epígrafe, ya que conocemos su nombre como patronímico de su hijo $C$. Antonius Aelianus, decurio de Augusta Vindelicorum.

9 M.H. Gallego Franco, Prosopografía, Onomástica y Sociedad del Imperio Romano. Las Esrtucturas Sociales. Las provincias de Rhaetia, Noricum, Pannonia Superior e Inferior, Tesis Doctoral, Valladolid, 1995, 217-221 (en prensa), los lulii son el grupo más importante cuantitativa y cualitativamente de Rhaetia, mientras que los Claudii ocupan el tercer lugar y los Antonii son uno de los significativos.
} 
los $/$ uli $^{10}$, los Claudii ${ }^{11}$, y los Antonii ${ }^{12}$. Los dos primeros son nomina de tipo imperial, del período julio-claudio, y aunque sus portadores no tengan esta adscripción cronológica, sus gentilicios ponen de relieve la romanización temprana de los antepasados de estos individuos, que en el caso de Tib. Claudius Euphrates eran extranjeros orientales, mientras que lulius Victor y lulius Verax parecen ya naturales de Rhaetia, y quizá también lo eran sus antepasados. En cuanto a Antonius, se trata de un gentilicio de tipo itálico, cuyos portadores seguramente descendían de colonos noritálicos asentados en la zona, o bien era indígenas que al recibir la ciudadania escogieron uno de estos gentilicios itálicos que por su frecuencia les eran familiares ${ }^{13}$. Los restantes son gentilicios poco frecuentes, como luvalius ${ }^{14}$ y Tenatius ${ }^{15}$, portados por individuos de origen galo el primero y noritálico el último, o bien Acutianius ${ }^{16}$, gentilicio de origen celta portado por un descendiente de indígenas romanizados que alcanzaron el derecho de ciudadanía, o Victorius ${ }^{17}$, nomen portado seguramente por un natural de la provincia, habida cuenta del especial éxito del cognomen Victor y sus derivados en Rhaetia ${ }^{18}$.

Los cognomina que acompañan a estos gentilicios son en su mayoría latinos, muy variados, aunque destaca la presencia de Victor ${ }^{19} \mathrm{y}$

10 H. SOLIN/O. SALOMIES, Repertorium nominum gentilium et cognominum Latinorum, Oims, 1988, 98; CIL III 5943, lulius Verax; CIL III 5816, Iulius Victor.

11 H.SOLIN/O. Salomies, Repertorium nominum..., 56; ClL III 5824, Tib. Claudius Euphrates.

12 W. Schulze, Zur Geschichte Lateinischer Eigennamen, Berlín, 1966, 124; CIL III 5800, P. Antonius y su hijo $C$. Antonius Aelianus.

13 Sobre la influencia del elemento noritálico en las onomáticas provínciales confróntese para Noricum: M. HARDING/G. JACOBSEN, «Norditalische Zuwanderung nach Celeia während der ersten zwei Jahrhunderte n. chr.», Acta Archaeologica Academiae Scientiarum Hungaricae, XLI, 1989, $227-232$.

${ }^{14} \mathrm{H}$. Solin/O. Salomies, Repertorium nominum..., 99; F. Wagner, «Neue Inschriften aus Raetien. Nachträge ZU Fr. Vollmer, Inscriptiones Baivariae Romanae», Bericht der RömischGermanischen Komission, XXXVII-XXXVIII, 1956-1957 [1958], n² 106, C. Iuvalius Atrectus y C. Iuvalius Acceptus, naturales de Augusta Treverorum.

15 W. SCHulze, Zur Geschichte..., 373; AE84, 707, P. Tenatius Essimus, natural de Iulia Tridentum.

16 H. Holder, Alt-Celtischer Sprachschatz, I, Graz, 1961, 34-36; H. Solin/O. Salomies, Repertorium nominum..., 5, pone de manifiesto que este gentilicio es sólo conocido en Rhaetia; CIL III 5830, Flabius Acutianius Serenus.

17 W. SCHULzE, Zur Geschichte..., 260, 333 S; CIL III 5833, Victorius Victorianus.

18 M..H. Gallego Franco, Prosopografía, Onomástica y Sociedad en el imperio Romano. Las Estructuras Sociales. Las provincias de Rhaetia, Noricum, Pannonia Superior e Inferior, Tesis Doctoral, Valladolid, 1995, 218 (en prensa), donde constatamos que pese a la variedad de cognomina latinos portados por los individuos de Rhaetia, sólo Victory sus derivados, como Victorinus o Victorina se repiten con una cierta entidad.

19 I. KaJAnto, The Latin Cognomina, Helsinki, 1965, 11, 18, 30bis, 57, 72, 89, 96, 98, 278. 
Victorianus ${ }^{20}$, característicos en cierto grado de Rhaetia. De forma minoritaria se constata la presencia de dos cognomina indígenas celtas, Atrectus, propio del área galo-romana ${ }^{21}$, y Essimnus, nombre del área vindelico-celta ${ }^{22}$, correspondiente al sustrato indígena de los Alpes y norte de Italia. El único caso de cognomen griego, Euphrates ${ }^{23}$, parece corresponder no a un individuo de origen liberto ${ }^{24}$, sino a un oriental, ya que la veta onomástica griega se perpetua en la familia, a través de su hijo Claudius Antigonus ${ }^{25}$. Es cierto que el cargo de sevir augustalis que ocupa Tib. Claudius Euphrates ${ }^{26}$ en Augusta Vindelicorum suele recaer en libertos, pero también es desempeñado en el Occidente Romano por un porcentaje mínimo de libres ${ }^{27}$. Finalmente, hay que señalar la presencia de dos negotiatores portadores de lo que parece ser un esquema onomástico de nombre único, dos cognomina latinos, lunianus y Pastor ${ }^{28}$. Es decir, que a pesar de que la mayor parte de los negotiatores situados en Rhaetia son ciudadanos, esta actividad comercial también es desempeñada por peregrinos de condición libre, a los que propicia una posición acomodada y una vía de integración en la vida municipal, ya que ambos reconstruyen un aedes del municipio en Augusta Vindelicorum. Su presencia manifiesta además los estadios intermedios de romanización en la configuración del cuerpo ciudadano de Augusta Vindelicorum.

En conclusión, en el grupo de negotiatores de Rhaetia predomina una onomástica personal altamente romanizada. Existe una hegemonía del es-

20 I. KajANTO, The Latin Cognomina..., 278.

21 H. HOLDER, Alt-Celtischer Sprachschatz, I, Graz, 1961, 271.

22 H. HOLDER, Alt-Celtischer Sprachschatz, I, Graz, 1961, 1474, donde constatamos la existencia de Essibnus en CIL III 5567, perteneciente al sur de Noricum, en la Baviera alemana; AE35, 103 , brinda otro testimonio de Essimnus.

23 H. Solin, Griech Personennamen in Rom, Berlín, 1982, 643.

24 H. Solin, Beitrage zur kenntnis der Griechischen Personennamen in Rom, Helsinki, 1971, 159; A. Lozano, "La transmisión de los antropónimos griegos en la epigrafía latina de Hispania», Actas del $V$ Coloquio sobre lenguas y culturas prerromanas de la Península lbérica, noviembre, 1989, Salamanca, 1993, 361-374, manifiestan la estrecha relación entre la onomástica griega y los libertos, al mismo tiempo que la tendencia entre los libertos a la latinización progresiva de la onomástica.

25 H. SOLIN, Griech Personennamen in Rom, Berlín, 1982, 199; K. DiETZ/G. WEBER, «Fremde in Rätien", Chiron, 1982, 438-439.

26 CIL III 5824.

27 J.P. MARTin, Les provinces romaines d'Europe Centrale et Occidentale. Société et Religions, París, 1991, 209.

28 F. WAGNER, "Neue Inschriften aus Raetien. Nachträge zu Fr. Vollmer, Inscriptiones Baivariae Romanae", Bericht der Römisch-Germanischen Komission, XXXVII-XXXVIII, 1956-1957 [1958], no 25; I. Kajanto, The Latin Cognomina..., 32, 148 (lunianus), 323 (Pastor). 
quema onomástico ciudadano y de una antroponimia muy latinizada, mientras que los elementos indígenas y griegos, muy minoritarios, nos ponen en contacto con una procedencia gala y autóctona los primeros, y grecooriental los segundos.

Desde el punto de vista social, los negotiatores de esta pequeña provincia forman un grupo de calidad, compuesto casi exclusivamente por ciudadanos romanos de condición libre, destacando la ausencia de libertos ${ }^{29}$. Sin duda, como grupo profesional, tienen un sentido altamente corporativo, siendo frecuentes las dedicaciones monumentales y votivas emanadas de asociaciones o collegia profesionales. Así en Castra Regina ${ }^{30}$, donde los negotiatores restauran un aedes cum signis en honor de Mercurius Censualis, y en Augusta Vindelicorum ${ }^{31}$, donde los negotiatores vestiariae et lintiariae ponen un aedes cum suis ornamentis. Los negotiatores brigantienses ${ }^{32}$ consagran un monumento votivo en su local de Brigantium, igual que aquellos situados en la zona del limes danubiano próxima a Nassenfels (cerca de Eichsttät, Baviera, Alemania) dedican una votiva ${ }^{33}$. Este sentido corporativo se pone de manifiesto también en la consagración a Hercules Augustus que ponen los bubularii ${ }^{34}$ o tratantes de ganado y que se halla en Batava Castra (Passau, Baviera, Alemania), un importante campamento militar en la desembocadura del Inn, en cuya vecindad se situaba además el importante núcleo aduanero de la statio Boiodurensis (Innstadt), en el límite con Noricum.

29 Es posible que algunos de ellos explicitaran precisamente su condición de ciudadanos romanos, seguramente una condición de privilegio en el medio social en que se encontraban insertos. Sin embargo los testimonios epigráficos que avalan esta posibilidad son problemáticos. CIL III 13542=AE86, 530 presenta una dedicactoria votiva perteneciente al local de una asociación de comerciantes, en la que la línea que expresa la origo de estos negotiatores Brigantienses está deteriorada, de manera que puede tratarse de un lugar geográfico abreviado con tres letras, desde la propia Roma, cives Rom(ani)?, hasta cualquier otro, sin descartar que en el caso de leer cives Rom(ani), que es la lectura de $\mathrm{ClL}$, se refiera a una condición jurídica de los individuos, y no a una origo geográfica; Fr. Vollmer, Inscriptiones Baviariae Romanae sive Inscriptiones provinciae

- Raetiae, adiectis aliquot Noricis Italicisque, München, 1915, nㅡ 249B parece mostrar una votiva dedicada por los negotiatores cives romani transdanubium consistentes, pero la realidad es que tal lectura es una recosntrucción del autor de un epigrafe totalmente fragmentado y muy deteriorado.

so CIL III 5943.

31 CIL III 5800.

32 CIL III 13542=AE86, 530.

33 Fr. VOLLMER, Inscriptiones Baviariae Romanae sive Inscriptiones provinciae Raetiae, adiectis aliquot Noricis Italicisque, München, 1915, $\mathrm{n}^{\circ} 249 \mathrm{~B}$.

${ }_{34}$ AE84, 708; K. DIETZ, «Passauer Viehhändler. Ein collegium bubulariorum auf einer Inschrift aus Passau", Chiron, 1987, 383-393. 
Los testimonios epigráficos ponen de manifiesto igualmente la especialización de estos comerciantes de Rhaetia en el intercambio de determinados productos. Destacan aquellos más demandados en la frontera, e incluso en el barbaricum, como los tejidos de calidad, la cerámica y el vidrio, el vino, y muy especialmente el ganado ${ }^{35}$. La sede de los mercaderes de tejidos parace situarse en la capital provincial, Augusta Vindelicorum, donde conocemos en el s. II d.C. una asociación de negotiatores vestiariae et lintiariae ${ }^{36}$, un negotiator vestiarius ${ }^{37}$ probablemente de época severa, y un negotiator artis purpurariae ${ }^{38}$ de la segunda mitad del s. $I 1$ o inicios del s. III d.C. En el ramo de la cerámica y el vidrio, situamos, seguramente ya en el s. III, un negotiator artis cretariae et flaturariae ${ }^{39}$ en Augusta Vindelicorum, y un negotiator artis cretariae ${ }^{40}$ en el núcleo de Lorch, situado en la zona del limes rético directamente en contacto con el de Germania Superior, cerca del importante campamento militar de Aquileia (Aalen, Baviera, Alemania), ámbito que contaba sin duda con un importante mercado militar. La desembocadura del Inn, donde situamos el fuerte de Batava Castra y la statio Boiodurensis, tiene un papel relevante, según nuestros testimonios, en el comercio de vino y ganado, ya que allí localizamos un negotians vinarius ${ }^{41}$ a finales del s. II d.C, así como un collegium de bubularii o tratantes de ganado ${ }^{42}$ ya en el s. III. Sin duda a este protagonismo contribuía su privilegiada situación como confluencia del Inn y el Danubio. Finalmente, también Augusta Vindelicorum estuvo conectada con el comercio de ganado, ya que allí encontramos un negotiator porcarius ${ }^{43}$ de época severa. En definitiva, es evidente que este tipo de mercancías (tejidos, cerámica, vino y ganado) eran destinadas a un mercado fronterizo, ya que todos los testimonios de comercian-

35 G. Alföldy, Noricum, Boston, 1974, 107-108; A. Mócsy, Pannonia and Upper Moesia, London, 1974, 127-129; C.R. WHITTAKER, Les Frontieres de l'Empire romain, París, 1989, 70; C.R. WHITTAKER, Frontiers of the Roman Empire. A Social and Economic Study, Baltimore, 1994, 104131; S.K. Drummond/L.H. Nelson, The Western Frontiers of Imperial Rome, New York, 1994, 91 96.

36 CIL III 5800, de la que son miembros $P$. Antonius y su hijo $C$. Antonius Aelianus, que alcanzó el rango equestre gracias a la fortuna acumulada por su padre.

37 CIL III 5816, lulius Victor.

38 CIL III 5824, Tib. Claudius Euphrates.

39 CIL III 5833, Victorius Victorianus.

40 IBR 293, Anonymus 3.

41 AE84, 707, P. Tenatius Essimnus.

42 AE84, 708; K. DIETZ, «Passauer Viehhändler. Ein collegium bubulariorum auf einer Inschrift aus Passau», Chiron, 1987, 383-393.

43 CIL III 14370. 
tes especializados en su intercambio se sitúan directamente en la zona limítrofe o en sus proximidades. En este sentido un importante centro de coordinación de las operaciones tuvo que ser la capital, Augusta Vindelicorum.

La posición económica privilegiada de la que disfrutaban, al menos un grupo selecto de negotiatores, se pone de manifiesto en las obras monumentales sufragadas por los mismos, como lunianus y Pastor ${ }^{44}$, que restauran un aedes del municipio en Augusta Vindelicorum, o un negotiator porcarius ${ }^{45}$ que restaura un aedes de su propio dinero en la capital, Augusta Vindelicorum, igual que un grupo de negotiatores ${ }^{46}$, también de Augusta Vindelicorum, que ponen un aedes cum suis ornamentis en esta ciudad, mientras que en Regina Castra otro grupo de negotiatores, en el que actúan como encargados de la dedicación lulius Verax y Anonymus $1^{47}$, restauran un aedes cum signis. Por otro lado, resulta revelador que todas estas obras monumentales estén consagradas a Mercurius, que es la divinidad romana protectora del comercio, los viajes y los intercambios ${ }^{48}$.

Al mismo tiempo, la fortuna, el prestigio y la influencia en la vida municipal fueron los avales que propiciaron la incorporación de estos individuos a las élites de gobierno municipales ${ }^{49}$. Dos de estos ciudadanos dedicados al comercio son decuriones de Augusta Vindelicorum, C. Antonius Aelianus ${ }^{50}$, que además alcanza el ordo equestre gracias a su riqueza, y Anonymus $2^{51}$. El monumento funerario de lulius Victor ${ }^{52}$ le sitúa en relación al senado municipal, ya que ordenó poner el monumento en su testamento, iniciativa que autoriza el decreto de los decuriones (decreto decurionum). Muy significativo es igualmente el cargo de sevir augustalis

44 F. WAGNER, "Neue Inschriften aus Raetien...", n² 25.

45 CIL. III 14370.

46 CIL III 5800.

47 CIL III 5943.

48 J.P. MARTIN, Les provinces romaines d'Europe centrale et occidentale. Société et Religions, París, 1991, 173-174; Cfr. B. COMBET-Farnoux, Mercure romain. Le culte public de Mercure et la fonction mercantile á l'epoque augustéenne, Roma, 1980.

49 Sobre las interesantes posibilidades de promoción de los comerciantes y mercaderes romanos en el Imperio cfr. J. ANDAEAU, «Mobilité sociale ef activités commerciales et financières", $L a$ mobilité sociale dans le monde romain. Actes du Colloque de Strasbourg (novembre 1988), ed. E. FRÉZOULS, Strasbourg, 1992, 21-32.

50 CIL III 5800.

51 CIL III 14370.

52 CIL III 5816. 
desempeñado por Tib. Claudius Euphrates ${ }^{53}$ en Augusta Vindelicorum, un cargo municipal de rango inferior que pudo usar como trampolín para ascender en el gobierno municipal ${ }^{54}$.

El predominio de los epígrafes monumentales y votivos sobre los funerarios evidencia sin duda el papel de intervención activa en la vida ciudadana desempeñado por los negotiatores réticos. La divinidad más honrada por éstos es Mercurius, el dios romano protector del comercio y el transporte. Un grupo de negotiatores ${ }^{55}$ le consagran un aedes en Castra Regina, monumento que además se realiza en honor de la domus divina y por la salud de Septimio Severo y Caracalla, C. Iuvalius Atrectus y $C$. luvalius Acceptus ${ }^{56}$ dedican sendas votivas también en Castra Regina, en honor de la domus divina, y un negotiator porcarius ${ }^{57}$ le consagra y restaura un aedes en Augusta Vindelicorum, igualmente en honor de la domus divina.

53 CIL III 5824, negotiator y sevir augustalis; cfr. CIL III 11045, Titius Domninus, augustalis de Brigetio (Pannonia Superior) y su hijo Titius Domninus sive Passer, negotians; J.P. MARTíN, Les provinces d'Europe centrale et occidentale. Société et Religions, París, 1991, 210 y C.R. WHITTAKER, Frontiers of the Roman Empire. A Social and Economic Study, London, 1994, 106-107, se hacen eco de la participación de los seviri y augustales en actividades comerciales y artesanales en las principales ciudades del Occidente romano, sobre todo ya en el s. II d.C.; así, en Gallia llama la atención la similitud en la distribución territorial de los negotiatores y los seviri-augustales, a lo largo de las principales rutas de abastecimiento de la frontera.

54 Esta promoción, que pudo realizarse a través de una adlectio: CIL III 3497, L. Seranius Serotinus, sevir, aedilis y decurio de Aquincum, la capital de Pannonia Inferior y uno de los principales centros comerciales del Danubio; AE72, 376, [---] Primitivus, natural de Savaria, la sede del concilium provinciae de Pannonia Superior, que desempeña el cargo de augustalis cum ornamentis decurionatus también en Aquincum. En otros casos la promoción pudo haberse materializado en la siguiente generación: CIL III 3456, Atilius Polio, augustalis de Aquincum, y su hijo G. Atilius Polianus, aedilicius y decurio. Estos casos se sitúan principalmente en el período posterior a las Guerras Marcomanas (166-180 d.C.), penetrando algunos ya en el s. III.

55 CIL III 5943.

56 F. WAGNER, “Neue Inschriften aus Raetien. Nachträge zu Fr. Vollmer, Inscriptiones Baivariae Romanae", Bericht der Römisch-Germanischen Komission, XXXVII-XXXVIII, 1956-1957 [1958], nº 106 .

57 CIL III 14370, donde Mercurius aparece bajo la advocación de Pater Matutinus, aunque K. DiETz/G. WEber, "Fremde in Rätien», Chiron, 1982, 441 lee Mercurius Matutinus en este mismo epígrafe. Cfr. A. HoLDER, Alt-Celtischer Sprachschatz, II, Graz, 1962, 483, donde se considera la raíz celta del epíteto Matutinus. El culto del Mercurius romano recubriria así anteriores cultos indígenas que dejan su huella en determinados epítetos que acompañan a esta divinidad. Recientemente, AE92, 1300 nos brinda una dedicación votiva hallada en Promontogno (Bondo, Grisons, Suiza), en el extremo sur de Rhaetia, consagrada a Mercurius Cissonius Matutinus. Este epíteto, Matutinus, también está constatado en Baden (Alemania), en CIL XIII 5234c y 5235 . 
Las otras tres divinidades honradas por los negotiatores de Rhaetia también son romanas. A Fortuna, ob rem grande auctam (por el patrimonio largamente engrandecido), consagran un monumento los negotiatores et cives romani? trans Danubium consistentes ${ }^{58}$ en Nassenfels (Eichsttät, Baviera, Alemania). Hercules Augustus, cuyo mito le relaciona con el ganado, es honrado por los bubularii ${ }^{59}$ de Batava Castra. Finalmente, contamos con una consagración de tipo universalista, dedicada por los negotiatores brigantienses ${ }^{60}$ a los Dii Deaeque y situada en el edificio-sede de su grupo. En definitiva, los negotiatores de Rhaetia se adcriben a cultos netamente romanos, divinidades protectoras de sus actividades económicas y beneficios, como Mercurius, Fortuna o Hercules. Al mismo tiempo, como corresponde a un grupo de calidad e influyente en la vida provincial, aparecen apoyando la ideología oficial a través de ciertas fórmulas que acompañan a sus dedicaciones munumentales y votivas, como in honorem Domus Divinae o pro salute Imperatoris Augusti..., tal y como ya hemos puesto de manifiesto.

La distribución geográfica de los testimonios de negotiatores en Rhaetia manifiesta una clara concentración de los mismos en la capital provincial, Augusta Vindelicorum (Augsburg, Baviera, Alemania) ${ }^{61}$, ciudad en la que situamos el $50 \%$ de los testimonios. Su infraestructura como capital provincial y su proximidad al limes hicieron de esta ciudad el principal centro de coordinación de los intercambios. El resto de los testimonios se sitúan en la línea fronteriza del limes y en proximidad con las principales rutas fluviales: el centro militar de Regina Castra ${ }^{62}$ (Regensburg, Baviera, Alemania); la zona militar y estratégica de Batava Castra-Statio Boiodurensis ${ }^{63}$ (Passau-Innstadt, Baviera, Alemania), en la confluencia del Inn y el Danubio; el núcleo de Lorch, próximo al campamento militar de Aquileia (Aalen, Baviera, Alemania), en la zona fronteriza limítrofe con Germania Superior, el núcleo de Nassenfels, cerca de Eichstätt (Baviera, Alemania), muy próximo a la línea de fuertes del limes norte rético; y el núcleo de

\footnotetext{
58 Fr. VOLLMER, Inscriptiones Baviariae Romanae sive Inscriptiones provinciae Raetiae, adiectis aliquot Noricis Italicisque, München, 1915, n²49B.

59 AE84, 708.

60 CIL III 13542=AE86, 530 .

61 Ptolomeo 2,12,4; 8,7,4; Itin. Anton., 232,1; 236,5; 241,4; 250,5; 258,2.11; 274,8; Not. Dign. Occ., 11,30.

62 Itin. Ant. 250; Tab. Peunt., Reginum.

63 Ptolomeo, 2,12,4; Itin. Ant., 249,5; Not. Dign. Occ., 34,44.
} 
Brigantium ${ }^{64}$, que es el situado más al sur de nuestros testimonios, en la zona de confluencia del Rin y el lago Constanza.

Finalmente, es bien significativo el hecho de que la adscripción cronológica de los testimonios de negotiatores en Rhaetia sea más bien tardía, rara vez anterior a mediados del s. II d.C., y muy frecuentemente de finales del s.ll y primer tercio del s. III. Por tanto, parece haber sido éste el período más dinámico para los intercambios comerciales en la provincia, un período de destacada prosperidad que coincide con la transformación del status provincial, ya que Rhaetia asciende al rango de provincia imperial pretoriana, y por tanto con el reforzamiento de su guarnición militar mediante el establecimiento de una legión, la legio III Italica, en Regina Castra ${ }^{65}$. En definitiva, los testimonios epigráficos de comerciantes y mercaderes en Rhaetia se centran en el período de más intensa y profunda romanización, a partir de las Guerras Marcomanas, que sin duda propició una etapa de prosperidad en el comercio. Además las actividades de intercambio tuvieron que verse reactivadas por el asentamiento de una legión en la provincia, lo que proporcionaba un importante mercado cautivo de individuos, y sus familias, con una evidente capacidad de consumo individual, a la que hay que añadir además las habituales necesidades de avituallamiento de todo contingente legionario, cuyo abastecimiento favorecía el Estado a través de una serie de privilegios otorgados a los mercaderes y comerciantes ${ }^{66}$. La localización de la mayor parte de los testimonios de negotiatores en la zona de frontera, o en territorios cercanos a ella, habla a favor de la importancia que tuvo en el comercio provincial el abastecimiento del limes y de las tropas en él asentadas.

En comparación con el análisis de los testimonios de negotiatores en Rhaetia, la vecina provincia de Noricum ofrece un contraste muy acusado. El antiguo reino celta de Noricum entró en contacto de forma temprana y pacífica con Roma a través de los mercaderes itálicos y sus agentes, que penetraron en la región atraídos por su extraordinaria riqueza minera, especialmente por sus minas de hierro ${ }^{67}$. Desde finales del s. I a.C. y du-

64 Estrabón, IV, 6,8; Plinio, N.H., 9,63; Ptolomeo, 2,12,3; 87,$3 ;$ Itin. Ant., 237,4; 251,2; 258,3; 259,$2 ; 277,4 ; 278,3 ;$ Not. Dign. Occ., 35,32.

65 J. WACHER, The Roman Empire, London, 1987, 34-35, 225.

66 C.R. WhitTAKER, Frontiers of the Roman Empire. A Social and Economic Study, BaltimoreLondon, 1994, 98-131.

67 J. WACHER, The Roman Empire, London, 1987, 161-170; E. EGGER, Die Stadt auf dem Magdalensberg ein Grosshan delsplatz, Österreichischen Akademie der Wissenschaften, Wien, 
rante el siglo I d.C., de forma más intensa con su incorporación como provincia al Imperio, y el s. II d.C., el sur de la provincia fue explotado por las grandes casas de comerciantes noritálicos, frecuentemente a través de agentes de status liberto ${ }^{68}$, cuya presencia ha dejado su huella en la onomástica provincial de Noricum, sobre todo en torno al primitivo centro económico de Magdalensberg (Carintia, Austria), Virunum (cerca de Klagenfurt, Carintia, Austria), y Celeia (Celje, Slovenia, Yugoslavia). Es el caso de ciertos grupos gentilicios de datación muy temprana, hacia el cambio de era, como los Barbii ${ }^{69}$, Postumii ${ }^{70}$, Poblicii ${ }^{71}$, Cispii ${ }^{72}$, Cominii $^{73}$, Gallii ${ }^{74}$, Priscii ${ }^{75}$, y también Antonii ${ }^{76}$, Cassii ${ }^{77}$, Castricii ${ }^{78}$, Cornelii ${ }^{79}$, Memmii ${ }^{80}$, Terentii ${ }^{81}$, Titii ${ }^{82}$ o Rufii ${ }^{83}$, todos de origen itálico, y cuyos miembros se integran ya en las aristocracias urbanas de los municipios del sur de la provincia en el s. III d.C. ${ }^{84}$.

Sin embargo, a pesar de esta efervescencia comercial altoimperial, los testimonios explícitos en Noricum de individuos cuya profesión sea la de negotiator son muy escasos. Es significativo, no obstante, que geográfi-

1961; S. DusanIC, "Aspects of Roman Mining in Noricum, Pannonia, Dalmatia and Moesia Superior", Aufstieg und Niedergang der römischen Welt, 6, 1977, 52-94.

68 J.K. KolosovSKA.JA, "Roman trading capital in Noricum", Vestnik Prevnej Istorii, 116, 1971, 57-70; G. PICcotTINI, «Die Stadt auf dem Magdalensberg-ein spätkeltischer und frührömisches Zentrum im südlichen Noricum", Aufstieg und Niedergang der römischen Welt, 6, 1977, 263-301; R. EGGER, "Ein Kapitel römischer Wirtschaftsgeschichte», Anzeiger der Österreichischen Akademie der Wissenschaften in Wien, XCII, 1956, 53-58; R. Egger, "Der Grossmarkt auf dem Magdalensberg", Wiener humanistische Blätter, 1962, 5, 34-37.

69 CIL III 4805, 4815, 4885, 4886, 5073, 5680, 11561, 11562, 11563, 11564, 11565; AE61, 73; AE82, 747.

70 CIL III 4951, 5251, 5266, 5269, 11585, 11586, 11587, 11601, 13520, 14103; AE78, 612; AE82, 747.

71 CIL V 717; AE53, 190; AE55, 98; AE57, 115; CIL III 4815, 4955.

72 CIL IX 6706, eran propietarios de una fábrica de sigillata en Arezzo.

73 CIL III 4784, 5066, 5264, 5680.

74 ClL III 5025, 12027E.

75 CIL III 4951, 13520, AE82, 747.

76 CIL III 5158.

77 ClL III 5075, 5158, 5196, 5249, 5257, 5355, 5578, 6499, 11552, 13524; AE04, 187.

78 AE38, 152; CIL III 5136, 5226.

79 CIL III 4719, 4980, 5055, 5216, 5228, 5275, 5544; ILI 390; AE85, 704.

$80 \quad$ AE38, 152.

81 CIL III 5143, 5237, 5538, 5568, 5605; AE73, 391; AE90, 777.

82 CIL III 4886, 4990A, 5053, 5389, 5444, 11601, 11603; AE86, 544.

83 CIL III 4813, 4965, 5199, 5268, 5281; AE89, 596.

$84 \mathrm{M}$. HARDING/G. JACOBSEN, «Norditalische Zuwanderung nach Celeia während der ersten zwei Jahrhunderte n. chr.", Acta Archaeologica Academiae Scientiarum Hungaricae, XLI, 1989, 227-232. 
camente los pocos negotiatores que conocemos se centren en los dos núcleos más importantes del sur de la provincia. Nos referimos a la capital provincial, Virunum ${ }^{85}$, que asumió el papel de centro económico y administrativo antes desempeñado por Magdalensberg ${ }^{86}$, y Celeia ${ }^{87}$, situada en el nudo fluvial del Savus (Sava) y Adsalluta (Savinja). Los testimonios de Virunum son los más tempranos, y se adscriben a esa etapa de explotación minera capitalista de la provincia. Allí situamos a Cadius Primus y Horatius Antripatus Pataris (filius?) ${ }^{88}$, en lo que parece ser una dedicatoria de fundación, junto con consagración votiva, de una sala de uso comercial, fechada por los cónsules bien hacia el año 23 a.C. o 12 a.C.

Desde el punto de vista onomástico, ambos individuos portan un esquema onomástico de duo nomina, es decir, de nomen+cognomen. Tanto Cadius ${ }^{89}$ como Horatius ${ }^{90}$ son gentilicios que no aparecen en ningún otro lugar de la provincia. Van acompañados, el primero, por un cognomen latino muy común, Primus ${ }^{91}$, y el segundo por uno griego, Antipatrus ${ }^{92}$. Por tanto, parece tratarse de individuos ajenos a Noricum, cuya presencia en la provincia debió ser efímera y no cristalizó en la fundación de un grupo gentilicio provincial. La aparición de sus nombres en conexión con esta sala para actividades comerciales apunta claramante a que estarnos en presencia de dos hombres, de origen itálico, como manifiestan sus gentilicios ${ }^{93}$, dedicados al comercio. Sin embargo, más que dos negotiatores, debe tratarse de dos agentes de origen liber-

85 Ptolomeo, 2,11,9; 2,13,3; Plinio, N.H., 3,146; Itin. Ant., 276,5; H. VeTters, «Virunum», Aufstieg und Niedergang der römischen Welt, 6, 1977, 302-354; J. WACHER, The Roman Empire, London, 1987, 224, Virunum será la capital provincial hasta el s. III, en que tras el ascenso de la provincia al rango pretoriano y la ubicación de una legión en Lauriacum, la capitalidad se trasladó al núcleo de Ovilaba, más al norte y por consiguiente más cercano al limes, aunque en Virunum siguió residiendo el procurator de finanzas.

86 E. EGGER, Die Stadt auf dem Magdalensberg ein Grosshan delsplatz, Österreichischen Akademie der Wissenschaften, Wien, 1961; R. Egger, «Der Grossmarkt auf dem Magdalensberg", Wiener humanistische Blätter, 1962, 5, 34-37; G. Piccottini, «Die Stadt auf dem Magdalensberg-ein spätkeltischer und frührömisches Zentrum im südlichen Noricum», Aufstieg und Niedergang der römischen Welt, 6, 1977, 263-301.

87 Plinio, N.H., 3,146; Ptolomeo, 2,13,3; Itin. Ant., 129,4.

88 AE65, 262.

89 W. SCHULZE, Zur Geschichte..., 76, señala el origen etrusco del nomen.

90 W. SchulzE, Zur Geschichte..., 356, 483, señala un posible doble origen, etrusco y latino, del nomen.

91 I. KAJANTO, The Latin..., 29, 30, 73-77, 134, 291.

92 H. Solin, Griech Personennamen..., 21, 22.

93 Cadius se constata en la Península Itálica, cfr. CIL IX 3050, 6086.14, CIL X 1158; también Horatius, cfr. CIL V 2965, 5289, CIL VI 200. 
to, que actuando en representación de ricos comerciantes itálicos formarían una sociedad de explotación minera, todo ello en ese marco de temprano aprovechamiento capitalista del sur de la provincia por las casas de mercaderes itálicos, cuya sede principal paracen haber sido las tabernae descubiertas en Magdalensberg ${ }^{94}$. En efecto, sorprende que Cadius Primus y Horatius Antipatrus no porten un esquema onomástico de tria nomina, ya que es poco común esta ausencia del praenomen en un momento tan temprano, de finales del s. I a.C. Si a ello añadimos el tipo de cognomen que ostentan, uno latino extremadamente común ${ }^{95}$, y otro griego ${ }^{96}$, podemos pensar que se trata no de hombres de condición libre, sino de libertos ${ }^{97}$. El objeto de su consagración votiva, Zeus Jzonios, expresado en griego - quizá por influjo de la corriente helénica tardorepublicana-, es un Zeus subterráneo (jzonios) identificable con el también griego Hades Plutón («El Rico») y con el romano Dis Pater. Se trata, en definitiva, de un dios subterráneo, padre de las innumerables riquezas de la tierra, agrícolas y mineras ${ }^{98}$. Si el negocio de Primus y Antipatrus era, como parece, la minería, no es de extrañar que invocaran para su sociedad la protección de esta divinidad de las riquezas subterráneas.

A otro ámbito distinto corresponde ya el testimonio del negotians Aurelius Adiutor ${ }^{99}$, que nos brinda un epígrafe funerario de Celeia, y que cronológicamente hay que situar en un momento más avanzado del

94 AE79, 440 A y B; E. EGGER, Die Stadt auf dem Magdalensberg ein Grosshan delsplatz, Österreichischen Akademie der Wissenschaften, 79, Wien, 1961, 10 n. ${ }^{\circ} 81,16$ n. ${ }^{\circ} 218,27$; R. EGGER, «Der Grossmarkt auf dem Magdalensberg", Wiener humanistische Blätter, 1962, 5, 34-37.

95 J. ZAJAC, «I cognomina dei patroni. Nell'indicazione dello status nei nomi propi dei liberti nella regio X Augustea", Acta Antiqua Academiae Scientiarum Hungaricae, 33, 1990-1992, 357358 , donde se señala que cognomina ampliamente difundidos en la onomástica latina, como Primus/a, Maximus/a, Magnus/a, Secundus/a, Proculus/a se encuentran con cierta frecuencia como cognomina de patronos que a su vez debieron de ser libertos.

96 H. Solin, Beitrage zur kenntnis der Griechischen Personennamen in Rom, Helsinki, 1971, 159; A. LOZANO, "La transmisión de los antropónimos griegos en la epigrafía latina de Hispania», Actas del $V$ Coloquio sobre lenguas y culturas prerromanas de la Península lbérica, noviembre, 1989, Salamanca, 1993, 361-374.

${ }_{97} \mathrm{AE} 79,440 \mathrm{~A}$ y $\mathrm{B}$, nos ofrece los nombres de varios esclavos o libertos, Surulus, Volubilitanus y [---]us en la primera, y Orosius y Volubilitanus en la segunda, que actuarían como agentes de mercaderes itálicos. Las inscripciones se han hallado en tiendas de Magdalensberg, se fechan en el reinado de Claudio, y les relacionan con el comercio de objetos metálicos, como sellos (anulos) y fuentes (cumbae).

98 P. Grimal, Diccionario de la Mitología Griega y Romana, Barcelona, 1991 (ed. 1951), 142, 221,436 .

99 CIL III 5230. 
Imperio, en el s. III. Este individuo es portador de un esquema onomástico de duo nomina, por lo demás característico del s. III, periodo en el que la mención del praenomen en la epigrafía había caído ya en desuso. El nomen gentilicio Aurelius ${ }^{100}$ indica que seguramente él mismo, o sus padres, recibió los derechos de ciudadanía a partir de la Constitutio Antoniniana de Caracalla (212 d.C.). Acompaña en este caso su nomen de un cognomen latino, Adiutor ${ }^{101}$. En definitiva, todavía en el s. III Celeia seguía siendo uno de los principales centros de intercambio comercial del sur de Noricum, atrayendo a comerciantes extranjeros, como es el caso del propio Aurelius Adiutor, cives Afer, es decir, natural del norte de África ${ }^{102}$.

El volumen de testimonios de negotiatores constatado en la provincia de Pannonia, aún siendo mucho más notable que el de Noricum, es todavía inferior al de Rhaetia, a pesar de que las dos Pannoniae constituyen una provincia de mucha mayor entidad territorial que Rhaetia, y con una superioridad numérica abrumadora de sus testimonios epigráficos. En conclusión, Rhaetia aporta el $52,6 \%$ al total de negotiatores recogidos en nuestro cuadro, mientras que Pannonia aporta un $39,4 \%$ y Noricum casi el $8 \%$. Desde el punto de vista onomástico, el conjunto de negotiatores de Pannonia porta mayoritariamente un gentilicio, bien en un esquema de tria nomina $(40 \%){ }^{103}$ o de duo nomina (40\%). La aparición de uno u otro parece responder al momento cronológico, ya que la mención del praenomen se hace poco frecuente desde finales del s. "I y ya en el s. III d.C. Sólo un individuo conserva un esquema de tria nomina en este período avanzado ${ }^{104}$, frente al predominio del duo nomina.

100 W. Schulze, Zur Geschichte..., 445 s., 468.

101 I. Kajanto, The Latin..., 360.

$102 \mathrm{AE79}, 440 \mathrm{~A}$ y $\mathrm{B}$ se hace eco de la posibilidad de relaciones comerciales entre Noricum y Mauritania, de manera que mercaderes norteafricanos irían a Magdalensberg a comprar objetos de hierro ya en los inicios del s. I, aunque finalmente se decanta por la hipótesis de que Volubilitanus sea un esclavo o liberto agente de un mercader itálico; cfr. R. THOvENOT, «Deuz commerçants de Volubilis dans le Norique», Bulletin d'archéologie marocaine, VIII, 1968-1972, 217-219; M. EuzEnNAT, "Le Marocain du Magdalensberg», Antiquités africaines, XIV, 1979, 123-128; Los testimonios de CIL III 11701 (Aurelius Bassus, Aurelius Maximus y Aurelius Sabinus) e ILI 389 (Aurelius Gaianus) evidencian la presencia de una colonia de ciudadanos de origen sirio en Celeia, en el s. III, quizá atraídos por las posibilidades comerciales de la ciudad.

103 Incluimos entre los portadores de tria nomina a $C$. Trotedius, de CIL III 14354.22, cuyo nombre se expresa en genitivo acompañando al de un esclavo, por lo que se omite su cognomen.

104 AE82, 803, C. lulius Sextimus, datado a finales del s. 11 o ya en el s. III d.C. 
En global, los gentilicios imperiales son poco frecuentes, aunque constatamos la presencia de lulius ${ }^{105}$, Aurelius ${ }^{106}$ y Septimius ${ }^{107}$ en un período ya avanzado del período romanizador, en el s. III d.C... Sin embargo, el grupo mayoritario, muy variado, es el formado por los nomina de origen itálico y occidental, como Atilius ${ }^{108}$, Titius ${ }^{109}$ y Valerius ${ }^{110}$, algunos de ellos poco frecuentes, como Canius ${ }^{111}$, Domatius ${ }^{112}$, Satellius ${ }^{113}$ y Trotedius ${ }^{114}$,

105 AE62, 383, lulius Senilis; AE82, 803, C. lulius Sextinus; H. Solin/O. SALOMIES, Repertorium nominum gentilium..., 98.

106 AE10, 134, Aurelius Messio; W. SCHulzE, Zur Geschichte..., 445 S., 468.

107 CIL III 10557, Septimius Colonus Attusonius; W. SCHULZE, Zur Geschichte..., 229.

108 AE78, 635, Q. Atilius Vo(l)t(inia tribu) Primus; W. SchulzE, Zur Geschichte..., 151, 440, señala el origen etrusco del nomen; Por otro lado, la tribu Voltinia está bien constatada en la Península Itálica: CIL V 5100, 5126, 5128, 5130, 5132, 5138, 5154, 5156, 5158, 5164, 5175, 5196, 5197, 5198; CIL X 1403 c.17.

109 CIL III 11045, Titius Domninus sive Passer; W. SCHULZE, Zur Geschichte..., 243 A, 425, señala el origen etrusco-latino del nomen.

110 CIL III 10430, L. Valerius Italus; H. Solin/O. SALomies, Repertorium nominum gentifium..., 197; R.C. KNAPP, Latin Inscriptions from Central Spain, Los Ángeles, 1992, 352, incide en la amplia difusión del nomen Valerius en el Imperio, siendo especialmente popular entre los soldados y en las provincias de sustrato celta; además, el cognomen Italus parece reforzar la posibilidad de que este individuo fuera descendiente de itálicos.

111 CIL III 4250, T. Canius Cinnamus, liberto; W. SCHULZE, Zur Geschichte..., 142, 144, señala el origen etrusco de este nomen, constatado, por lo demás, bien en Italia: CIL V 755, 776, 992, $1269,1270,2856,2585,8307,8353$; incluso se constata entre libertos, como CIL V 978, 1270; Tambiéri el cognomen Cinnamus se encuentra constatado en Italia, cfr. CIL IX 3580 (siervo imperial), 3641, 4549 (liberto), 5301, 6082.21; CIL X 1403.A1, 1403.6L, 1403.G3, 1403.6L, 2380, 4697, 4933, 8113; CIL XI 725, 978, 1060, 3996 (liberto), 5427, 6239, 7838.

112 CIL III 4251=AE92, 1393, P. Domatius Ter(etina tribu) Citio; H. Solin/O. Salomies, Repertorium nominum gentilium..., 69; Encontramos el nomen Domatius Italia, incluso portado por libertos: CIL IX 1713 (liberto), CIL X 778 (varios libertos), 5121; También la tribu Teretina está bien constatada en la Península Itálica: cfr. CIL X (pars posterior), p. 1.139.

113 AE38, 163, P. Satellius Scap(tia tribu) Sodalis; W. SCHULZE, Zur Geschichte..., 225, 444, señala el origen etrusco-latino del nomen; El gentilicio se ha constatado en Italia: CIL IX 5618 (Iiberto); CIL XI 2142, 2145, 6604, 7140, 7143; También la tribu Scaptia es bien conocida en Italia: CIL V 925, 1765, 1767, 1779, 2166, 7258; CIL X 211, 1401, 1403, 1750, 6097, 6493; Por otro lado $P$. Satellius Sodalis aparece vinculado al grupo gentilicio de los Varii a través de su avunculus, $Q$. Varius Modestus. Los Varii se convirtieron en una familia de calidad en Celeia (Noricum), probablemente gracias a la fortuna adquirida a través de las actividades comerciales y artesanales, y donde conocemos algunos de sus miembios en el ordo equestre: cfr. CIL III 5214, AE87, 796; M.H. Gallego, Onomástica, Prosopografía y Sociedad en el Imperio Romano. Las Estructuras Sociales. Las provincias de Rhaetia, Noricum, Pannonia Superior e Inferior, Valladolid, 1995, 498505 (en prensa).

114 ClL III 14354.22, C. Trotedius; H. Solin/O. Salomies, Repertorium nominum gentilium..., 191, que le da como caso único en la epigrafía latina. Sin embargo conocemos en W. SCHULZE, Zur Geschichte..., 305 y 427 los nomina Trottedius y Truttedius, de origen etrusco-latino. Ambos son constatados en Italia: cfr. respecto al primero CIL V 2710 (liberto) y respecto al segundo CIL V 1946 (liberta), 2711 (liberta), 3783, 3784 (liberto), 3785, y CIL IX 5931. 
y que se extienden sobre todo a lo largo de las dos primeras centurias del Imperio. A pesar del origen itálico del nomen Antonius ${ }^{115}$, este grupo gentilicio muestra en Pannonia un doble componente foráneo, por un lado itálico ${ }^{116}$ y por otro oriental ${ }^{117}$, pareciendo ser éste último el más adecuado a los negotiatores Antonii de nuestro cuadro ${ }^{118}$. En cuanto a los cognomina que acompañan a los gentilicios, el predominio de los de tipo latino es aplastante. Sólo Antonius Gelasius ${ }^{119}$ porta un cognomen griego, mientras que huellas de onomástica indígena encontramos en los cognomina de P. Domatius Citio ${ }^{120}$ y Septimius Colonus Attusonius ${ }^{121}$. Éste último usa además un sistema de doble cognomen, en este caso mixto, ya que Colonus ${ }^{122}$ es de origen latino y Attusonius indígena. Algo similar encontramos en la onomástica de Titius Domninus sive Passer ${ }^{123}$, que usa dos cognomina latinos ${ }^{124}$, el segundo de ellos como una especie de

115 W. SCHULZE, Zur Geschichte..., 124, señala el origen etrusco-itálico de este nomen.

116 CIL III 11209, M. Antinius Celer, veteranus legionis XIIII Geminae Martiae Victricis, de Ticinum (Carnuntum, II d.C.); CIL III 14358.13A, L. Antonius Magnus, miles legionis X Geminae, de Bononia (Carnuntum, finales I d.C.).

117 AE29, 205, M. Antonius Lentinus, miles legionis XV Apollinaris, de Antiochia (Carnuntum, finales I d.C.); AE29, 206, M. Antonius Rufus, miles legionis XV Apollinaris, de Cyrrhus (Carnuntum, finales I d.C.); M. MIRkovic, "Sirmium et l'armée romaine», Arheoloski Vestnik, 41, 1990, 633, C. Antonius Victor, optio spei legionis III Gallicae, también sirio (Sirmium, finales II-inicio III), donde se señala también la frecuencia del gentilicio Antonius entre los soldados reclutados en Oriente.

${ }_{118}$ ILI 289, Antonius Barbilus, que dedica a una divinidad oriental, Mithra en Mursa, ya a finales del s. II o en el s. III d.C.; AE69/70, 464, Antonius Gelasius, que porta un cognomen griego (cfr. H. SoLIN, Griech Personennamen..., 1276) que posiblemente revele una veta oriental en la familia, además de que su testimonio, del s. II, pertenece a un núcleo de fuerte presencia militar como Brigetio; S.K. Drummond/L.H. NeLson, The Western Frontiers of Imperial Rome, New York, 1994, 204-208, resalta que los cultos orientales, como el de Mithra, se extienden por la frontera danubiana gracias a los desplazamientos de mercaderes sirios y tropas reclutadas en Oriente; M.H. Gallego Franco, Prosopografía, Onomástica y Sociedad en el Imperio Romano. Las Estructuras Sociales. Las provincias de Rt:aetia, Noricum, Pannonia Superior e Inferior (Tesis Doctoral), Valladolid, 1995, 742-771, 993-1004, 1655, 1657, 2008 (en prensa), señala la importancia de la penetración de elementos orientales en el Danubio a partir de las Guerras Marcomanas.

119 AE69/70, 464; H. SoLIN, Griech Personennamen.., 1276.

120 CIL III 4251=AE92, 1393, dos lecturas del cognomen: la de CIL es Tergitio y la de AE92 es Citio; En todo caso ninguna de las dos es latina, cfr. A. HOLDER, Alt-Celtischer Sprachschatz, II, Graz, 1962, 1796 (Tergenius) y A. HoLDER, Alt-Celtischer Sprachschatz, I, Graz, 1961, 1034-1035, que atestigua los antropónimos Cittius, Citto, Cittus y Citus en la zona danubiana; 1001-1002 recoge Citio-Cetion, topónimo de Noricum, así como la raíz celta ceto- que pone en relación con topónimos de Noricum, Rhaetia y Gallia.

121 CIL III 10557; A. Holder, Alt-Celtischer Sprachschatz, I, Graz, 1961, 278.

122 I. Kajanto, The Latin..., 321.

123 CIL III 11045.

124 I. Kajanto, The Latin..., 135, 362 (Domninus), 18, 126, 331 (Passer). 
apodo, dando a entender que era conocido por cualquiera de los dos nombres. En todo caso, este fenómeno de acompañar el gentilicio de más de un cognomen pertenece a esquemas onomásticos de un momento ya avanzado, del s. III d.C. Finalmente, hay que destacar que sólo un individuo, Atta Bataionis $f$. ${ }^{125}$, no incluye un gentilicio en su esquema onomástico, que se compone, en cambio, de un nombre único, indígena celta, acompañado del patronímico, es decir, del nombre del padre en genitivo, también de origen celta. Parece tratarse de un peregrino sin derechos de ciudadanía que también se dedicaba a actividades comerciales.

En conclusión, este grupo de negotiatores y comerciantes de Pannonia está compuesto mayoritariamente por ciudadanos portadores de una onomástica altamente latinizada y romanizada, en la que predomina la componente itálica. Así, un grupo importante de ellos son de origen itálico, o descendientes de familias itálicas, que se asentaron en la provincia en las primeras etapas de la romanización (s. 1-Il d.C.), atraídos por sus posibilidades de hacer negocios (riqueza agropecuaria y minera, abundancia de tropas asentadas, proximidad del limes y de los territorios bárbaros libres). En cambio, los miembros de familias gentilicias con nomina imperiales han dejado su testimonio en un momento más avanzado del proceso romanizador, de finales del s. "y s. III d.C., y parecen ya fundamentalmente naturales de la provincia.

En conjunto, los negotiatores y comerciantes ubicados en Pannonia son hombres de calidad, ciudadanos romanos, la mitad de los cuales disfrutaban de esta situación privilegiada ya en los dos primeros siglos del Imperio, cuando los derechos de ciudadanía todavía no habían alcanzado su máxima extensión en la provincia. Aunque la mayor parte de ellos son hombres libres, constatamos la presencia de un liberto de origen noritálico, T. Cannius Cinnamus ${ }^{126}$, negotiator del que conocemos su monumento funerario en la zona del limes, cerca de Scarbantia. En el ámbito corporativo, conocemos un collegium negotiantium en Aquincum ${ }^{127}$, aunque es evidente que las asociaciones profesionales del mundo del comercio son más numerosas y de actividad más vigorosa en la provincia

125 AE72, 420; A. HOLDER, Alt-Celtischer Sprachschatz, I, Graz, 1961, 272-273, 358.

126 CIL III 4250.

127 CIL III 10430, donde L. Valerius Italus consagra un monumento votivo en honor del optimus collegium negotiantium de Aquincum; CIL III 19771 menciona en el ámbito del transporte, un collegium naviculariorum en Emona (Pannonia Superior). 
Rhaetia, donde además se aglutinaban los comerciantes especializados en el intercambio de determinados productos. En Pannonia sólo Septimius Colonus Attusonius ${ }^{128}$, mulio en Aquincum, aparece como comerciante especializado en un producto concreto, el ganado. De hecho, es bien constatada la importancia del comercio de ganado y sus derivados (carne, cuero...) para el limes danubiano y las numerosas tropas allí asentadas, en el cual llegaban a participar los pueblos bárbaros del otro lado de la frontera ${ }^{129}$.

Más frecuentemente los testimonios de comerciantes de Pannonia suelen ser individuales, designando su profesión con el término general de negotiator. Escapan a esta denominación los tratantes de ganado, a los que nos hemos referido, un canabarius y un conductor. Antonius Gelasius ${ }^{130}$, hermano del primus pilus Antonius Agrippinus, se declara canabarius, es decir, propietario de alguna bodega o almacén en Brigetio, uno de los principales fuertes militares del limes. Por otro lado, C. Iulius Sextinus ${ }^{131}$ aparece como conductor, es decir, un individuo que cierra con el ordo kanabarum, el senado de la villa militar de Aquincum, un contrato sin duda relacionado con el abastecimiento de determinados productos. Sextinus financia entonces una generosa obra monumental, ubicada en suelo público, para corresponder al beneficio por él recibido.

El estímulo que las necesidades de abastecimiento de las tropas y las posibilidades de intercambio con los pueblos libres allende el limes ejercieron para el despegue productor y comercial de Pannonia se refleja significativamente en la trayectoria personal de negotiatores como $Q$. Atilius Primus ${ }^{132}$ y Titius Domninus sive Passer ${ }^{133}$, que caracterizan al limes como una franja porosa y flexible, una zona dinámica de intercambios ma-

${ }^{128}$ ClL. III 10557; W. JOBST/E. WEBER, «Ein Heiligtum der Pferdergöttin Epona in Carnuntum (?)", Acta Archaeologica Academiae Scientiarum Hungaricae, XLI, 1989, 355; AE91, 1308=AE92, 1417 da a conocer un grupo de superiumentarii y muliones en Carnuntum, personal subalterno, quizá servil, encargado de los desplazamientos del legado provincial.

129 A. Mócsy, Pannonia and Upper Moesia, London, 1974, 127-129; C.R. WHITTAKER, Les Frontieres de l'Empire romain, París, 1989, 70; C.R. WHITTAKER, Frontiers of the Roman Empire. A Social and Economic Study, Baltimore, 1994, 104-131; S.K. DRummond/L.H. NELSON, The Western Frontiers of Imperial Rome, New York, 1994, 77-97; J. WACHER, The Roman Empire, London, 1987, 227, señala la existencia de un notable mercado porticado en Carnuntum, dedicado al comercio del ganado, una de las actividades principales de la zona.

$130 \mathrm{AE} 69 / 70,464$.

131 AE82, 803.

132 AE78, 635.

133 CIL III 11045. 
teriales y culturales ${ }^{134}$. El primero de ellos desarrolló su carrera militar como interprex y centurio de la legio XV Apollinaris en la segunda mitad del s. I d.C., pero al mismo tiempo aprovechó sus conocimientos del idioma de los pueblos indígenas fronterizos para internarse en el mundo de los negocios. Así, en su monumento funerario de Brigetio, zona en contacto con el limes, se expresa su profesión de negotiator, comerciante que seguramente intercambiaba manufacturas romanas por productos locales, actividad que pudo iniciar todavía como militar y continuar tras su licenciamiento. Incluso se ha querido ver en el oficio de negotiator de este individuo un cierto carácter oficial, convirtiéndole en un controlador del comercio fronterizo con los bárbaros ${ }^{135}$. Titius Domninus sive Passer, negotians del s. III, tiene su monumento funerario en Brigetio, donde consta que fue asesinado por los bárbaros (interfecto a barbaris), posiblemente en el curso de sus actividades comerciales, en virtud de las cuales penetraba en el barbaricum y tomaba contacto con los pueblos del otro lado de la frontera.

La mayor parte de los testimonios de negotiatores de Pannonia se adscriben a dedicaciones funerarias y votivas, destacando, en contraste con Rhaetia, la poca presencia de las dedicaciones monumentales. Por ello adquiere un carácter excepcional la obra monumental de $C$. lulius Sextinus ${ }^{136}$, conductor en Aquincum, ciudad a la que obsequia con un arcum cum ianuis tegula tectum, que hizo de su propio dinero (impendiis suis fecit), obra realizada además en suelo público y aprobada por decreto de los decuriones, con la que agradece al ordo el beneficio del contrato recibido. En consecuencia, Sextinus es el comerciante de Pannonia que hace ostentación epigráfica de un mayor nivel de riqueza. Sin embargo, también encontramos otros signos de fortuna entre los negotiatores de esta provincia, aunque no sean tan llamativos como la financiación de una obra monumental. Es, evidentemente, el caso de la posesión de esclavos o el patronazgo de libertos. Así, Q. Atilius Primus ${ }^{137}$ es patrono de la liberta Atilia Fausta y dueño del siervo Martialis en la zona de Brigetio, $P$.

\footnotetext{
134 C.R. WHITTAKeA, Les Frontières de I'Empire romain, París, 1989, 36-37, 59-73; Idem, Frontiers of the Roman Empire. A Social and Economic Study, London, 1994, 98-131.

135 C.R. WHITTAKER, Frontiers of the Roman Empire. A Social and Economic Study, London, 1994, 117; T. Kolník, «Q. Atilius Primus-interprex centurio und negotiator», Acta Archaeologica Academiae Scientiarum Hungaricae, XXX, 1978, 61-75.

136 AE82, 803.

137 AE78, 635.
} 
Domatius Citio ${ }^{138}$ es patrono de la liberta Domatia Vimpia, que además es su esposa, en Carnuntum, y $C$. Trotedius ${ }^{139}$ es dueño del esclavo Medus en Neviodunum.

Las consagraciones votivas de los comerciantes y negotiatores de Pannonia revelan una pluralidad de cultos, romanos, orientales e indígenas, y frecuentemente tienden a buscar una protección para ellos mismos y para sus actividades profesionales ${ }^{140}$. En Intercissa, Aurelius Messio ${ }^{141}$ consagra, pro salute sua, a Mercurius Lucrorum Potens, el poderoso dios romano del comercio y los beneficios. La dedicación de $L$. Valerius Italus ${ }^{142}$ a luppiter Optimus Maximus, luno, Mars y Neptunus en honor del collegium negotiantium de Aquincum auna el carácter oficial romano de la presencia de Júpiter y Juno Capitolinos con la protección de una divinidad como Neptunus, relacionada con la navegación y los transportes. De hecho, Medus, el siervo de C. Trotedius ${ }^{143}$, coloca en Neviodunum, en el sur de la provincia y a orillas del Sava, un ara consagrada a Neptunus Ovianus, es decir, al Neptuno protector de los puentes y del tránsito de los ríos. Finalmente, Silvanus es otra divinidad romana honrada por los comerciantes en la provincia, a quien lulius Senilis ${ }^{144}$ consagra un ara en un santuario cerca de Scarbantia, a inicios del s. III d.C.

Los cultos orientales hacen presencia en el mundo votivo de los comerciantes de Pannonia en un momento tardío, ya en el s. III. Así, Antonius Barbilus ${ }^{145}$ dedica a Deus Invictus Mithra en Mursa, y C. Iulius

138 CIL III 4251.

139 CIL III 14354.22.

140 Consagraciones votivas al Genius Comercii evidencian la importancia trascendental de las actividades de intercambio para la vida provincial de Pannonia: cfr. CIL III 3617, M. Aurelius Severinus dedica a Iuppiter, luno Regina, Genius Ciniaemus et Genius Comercii; CIL III 4288, Primitivus, esclavo del conductor publici portorii Illyrici lulius Proculus, octo servus y vilicus vicesimae, dedica al Genius Comercii et Negotiantium en Brigetio.

141 AE10, 134.

142 CIL III 10430.

143 CIL III 14354.22.

144 AE62, 383; El culto a Silvanus era especialmente popular en Pannonia, como Silvanus Domesticus, dios de hogar, o Silvester dios de los bosques y la caza, lo que le vinculaba especialmente al estamento militar. Quizá a este éxito contribuya un fenómeno de asimilación con algún culto indígena anterior, cfr. Z. FARKAS, «Notes sur le culte scarbantien de Silvanus Augustus", Acta Classica Universitatis Scientiarum Debreceniensis, VIII, 1972, 95-100; J.P. MARTín, Les provinces romaines d'Europe centrale et occidentale. Société et Religions, París, 1991, 176-177.

$145 \quad$ ILI 289. 
Sextinus a la Dea Syria y Baltis Dea en Aquincum. El culto a Mithra alcanzó gran difusión a lo largo del limes danubiano en el s. III, introducido precisamente por los comerciantes sirios y orientales y los soldados reclutados en Oriente ${ }^{146}$. El segundo monumento nos ofrece en cambio la asociación, propia del área de Aquincum ${ }^{147}$, de la diosa indígena pannonia Baltis ${ }^{148}$ con una divinidad oriental, la dea Syria, siguiendo una línea de sincretismo característica del mundo romano. Algunas de estas dedicaciones votivas muestran la adhesión de este grupo social a las estructuras oficiales y la autoridad establecida, como la de C. Iulius Sextinus a Syria y Baltis, consagrada pro salute Augusti.

La distribución geográfica de los testimonios de negotiatores y comerciantes en Pannonia gira claramente en torno a las importantes vías de comunicación que suponen los cursos fluviales y la importancia de la zona del limes. El $73 \%$ de los monumentos se ubican en los núcleos civiles-militares de la frontera, o próximos a ella, en concreto en Brigetio (Szöny, Hungria) ${ }^{149}$, Carnuntum (Petronell, Austria) ${ }^{150}$ y Scarbantia (Sopron, Hungría) ${ }^{151}$ en Pannonia Superior, y Aquincum (Budapest, Hungría) ${ }^{152}$ e Intercisa (Dunaújváros, Hungría) ${ }^{153}$ en Pannonia Inferior. Más al sur, la situación de los negotiatores es igualmente estratégica, en Mursa (Osijek, Croacia, Yusgoslavia) ${ }^{154}$, a orillas del Drava, en Pannonia Inferior, así como en Neviodunum (Drnovo, Slovenia, Yugoslavia) ${ }^{155}$ y Savaria (Szombathely, Hungría) ${ }^{156}$, en Pannonia Superior, la primera de ellas junto

146 S.K. Drummond/L.H. Nelson, The Western Frontiers of Imperial Rome, New York, 1994, 204-208.

147 CIL III 10393.

148 CIL III 10574, 10973; RIU 240.

149 Ptolomeo, 2,14,3; Itin. Ant., 246,2; 262,9; 263,2; 264,7; 265,3; Not. Dign. Occ., 33,51; Orosio, VII,32,14.

150 Plinio, N.H., 4,80; 33,45; Ptolomeo, 2,14,3; Itin. Ant., 247,2; 362,3.8; 266,14; 267,12; Not. Dign. Occ., 34,26 y 28.

151 Plinio, N.H., 3,146; Ptolomeo, 2,14,4; Itin. Ant., 233,6; 261,6; 262,7; 266,5; Not. Dign., 34,30 .

152 Ptolomeo, 2,15,4; Itin. Ant., 245; Tab. Peunt., Aquinco.

153 Itin. Ant., 245.

154 Ptolomeo, 2,15,4; 8,7,7; Itin. Ant., 131,1; 232, 6; 243,5; 265,5; 267,3; Eutropio, 9,8,1; 10,12, 1; Not. Dign. Occ., 32,52; Orosio, VII,29,12.

155 Ptolomeo, 2,14,4; Itin. Ant., 259,14; es esta una zona de intensos contactos con Dalmatia e Italia, en la que localizamos también miembros del grupo gentilicio de los Barbii, como el liberto Ti. Barbius Primus (cfr. ILI 1116), que nos son conocidos ya en Noricum como agentes comerciales de los Barbii noritálicos.

${ }_{156}$ Plinio, N.H., 3, 146; Ptolomeo, 2,14, 4; Itin. Ant., 233,5; 261,7; 262,6; 263,3; 266,4; Not. Dign. Occ. 5,$9 ; 7,82 ; 11,25$. 
al Sava, y la segunda próxima al Raba, que además es la sede del concilium provinciae y del culto imperial de Pannonia Superior ${ }^{157}$.

Desde el punto de vista cronológico, el $53 \%$ de los comerciantes atestiguados en Pannonia se sitúan en los dos primeros siglos del Imperio. En este período temprano predominan los testimonios de la mitad occidental de la provincia, que con Trajano se convierte en Pannonia Superior, y que es la mitad en la que la romanización sigue un paso más vivo. En cambio, los testimonios de la mitad oriental, Pannonia Inferior, se concentran en un momento más tardío, a partir de las últimas décadas del s. II y ya en el siglo III d.C., ya que es sobre todo a partir de las Guerras Marcomanas (166-180 d.C.) cuando el proceso romanizador cobra su máximo vigor en esta zona de la provincia. Si sólo Aquincum, la capital de Pannonia Inferior y fundamental núcleo militar y comercial del Danubio ${ }^{158}$, nos ofrece algún testimonio de negotiatores en el período altoimperial, Brigetio y Scarbantia son los dos núcleos de Pannonia Superior en los que constatamos la presencia de negotiatores en el s. III.

En conclusión, la presencia del colectivo profesional de negotiatores en las sociedades provinciales del Alto y Medio Danubio es desigual, siendo ésta importante en Rhaetia y Pannonia y sorprendentemente escasa en Noricum. Desde el punto de vista onomástico, los negotiatores de Rhaetia, Noricum y Pannonia son individuos muy romanizados, con una antroponimia altamente latinizada, en esquema de tria nomina o duo nomina. La incidencia de los nomina gentilicios imperiales entre ellos es escasa, siendo mucho más frecuentes los gentilicios no-imperiales, normalmente de procedencia itálica y occidental. La aparición de onomástica griega e indígena es muy puntual.

En cuanto a su status socioeconómico, se trata casi exclusivamente de hombres libres, que parecen disfrutar de los derechos de ciudadanía desde época temprana. Todos ellos disfrutan de una posición económica desahogada y prestigio social, pero los negotiatores de Rhaetia aparecen como un grupo especialmente dinámico, especializados en determinados productos

157 Cfr. J. FITZ, «Concilia provinciae in Pannonien», Festschrift A. Betz, 1985, 257-265.

158 K.Sz. PóczY, «Die Töpferwerkstätten von Aquincum», Acta Archaeologica Academiae Scientiarum Hungaricae, VII, 1956, 74-138; K.Sz. PóczY, «Die Rolle von kölner Kaufleuten in der Entwicklung der Zivilstadt Aquincum", Acta Archaeologica Academiae Scientiarum Hungaricae, XIII, 1961, sobre la influencia en la romanización de la ciudad de los mercaderes de Ara Agrippinensis, en Germania. 
(tejidos, cerámica y vidrio, vino y ganado), con una importante actividad corporativa, siendo además los que hacen una mayor ostentación de su riqueza en obras de evergetismo. Prueba de su influencia pública es que alguno de ellos se introduce en las aristocracias municipales de Augusta Vindelicorum. En Noricum los negotiatores se relacionan estrechamente con la explotación minera, mientras que en Pannonia no suelen explicitar su ámbito comercial. En todo caso, un indicador común de su bienestar económico en las tres provincias del Alto y Medio Danubio es el patronazgo de libertos y la posesión de esclavos. Añadiremos aquí que los monumentos funerarios que indican su edad de defunción son poco frecuentes, pero cuando contamos con el dato ésta suele ser elevada, hecho que habla a favor de un nivel de vida acomodado de estos comerciantes ${ }^{159}$.

Las preferencias religioso-votivas de este grupo muestran su adhesión a los cultos romanos, con una incidencia puntual de dioses orientales o indígenas, constatada sólo en Pannonia (Baltis, Syria, Mithra). El móvil principal de sus dedicaciones es invocar protección para su persona y sus negocios a la divinidad romana apropiada: Mercurius, Fortuna, Hercules, Pluton o Neptuno. Además, a través de sus consagraciones votivas estos comerciantes del Alto y Medio Danubio manifiestan su lealtad a las estructuras oficiales en fórmulas como in honorem domus divinae, pro salute Augusti o pro salute Augustorum.

La distribución geográfica de los testimonios de negotiatores de Rhaetia y Pannonia se centra en la franja norte del limes, es decir, los núcleos que siguen la línea del Danubio), y en los centros situados a lo largo de otras importantes vías fluviales (Sava, Drava, Raba, Rhin). En Noricum se centran en las zonas mineras del sur. Cronológicamente, los negotiatores de Rhaetia son de adscripción tardía, finales del s. II-s. III d.C., período en el que asistimos a una importante revitalización del comercio provincial, posiblemente favorecido por el final de las Guerras Marcomanas, el ascenso de grado de la provincia y la asignación de una legión a la guarnición de la misma. Noricum, y más claramente Pannonia, revelan una importante presencia de negotiatores ya desde los inicios del Imperio y a lo largo del periodo altoimperial. Factores como el abastecimiento del eleva-

159 AE78, 635, Q. Atilius Primus, 80 años, en Pannonia; CIL III 5824, Tib. Claudius Euphrates, 76 años, en Rhaetia; CIL III 4250, T. Canius Cinnamus, 70 años, en Pannonia; AE84, 707, $P$. Tenatius Essimnus, 57 años, en Rhaetia; ClL III 5830, Fla. Acutianius Serenus, 45 años, en Rhaetia; CIL III 5230, Aurelius Adiutor, 35 años, en Noricum; CIL III 11045, Titius Domninus sive Passer, 25 años, asesinado en Pannonia. 
do número de tropas allí estacionado, la presencia de un mercado militar cautivo con efectivo para gastar, y las vías de intercambio abiertas hacia Germania, Gallia y los pueblos libres de la frontera por el norte, y Dalmacia e Italia por el sur, explican este temprano dinamismo de las actividades comerciales y de transporte en Pannonia, y acabarían afectando igualmente a Noricum y Rhaetia. 


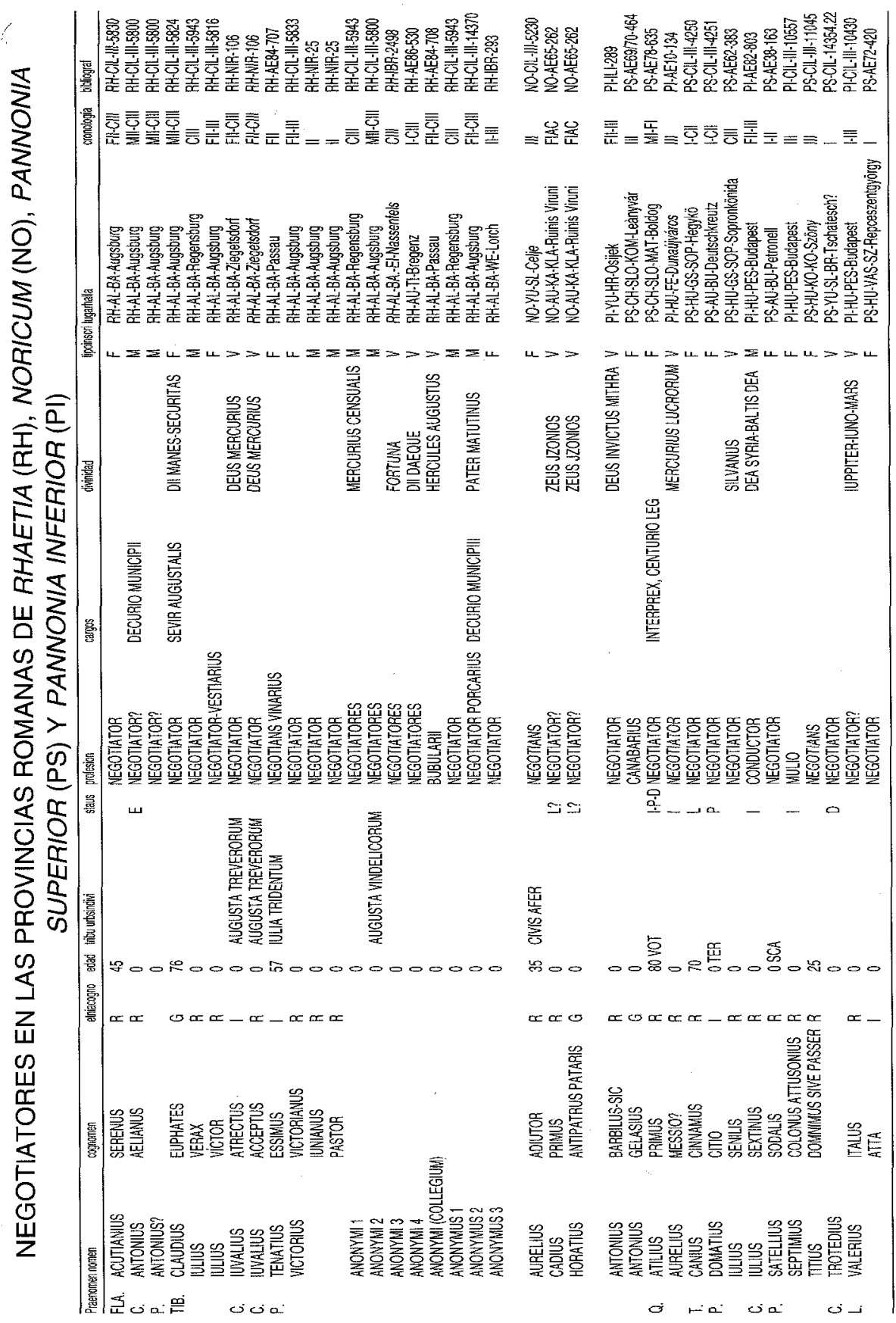




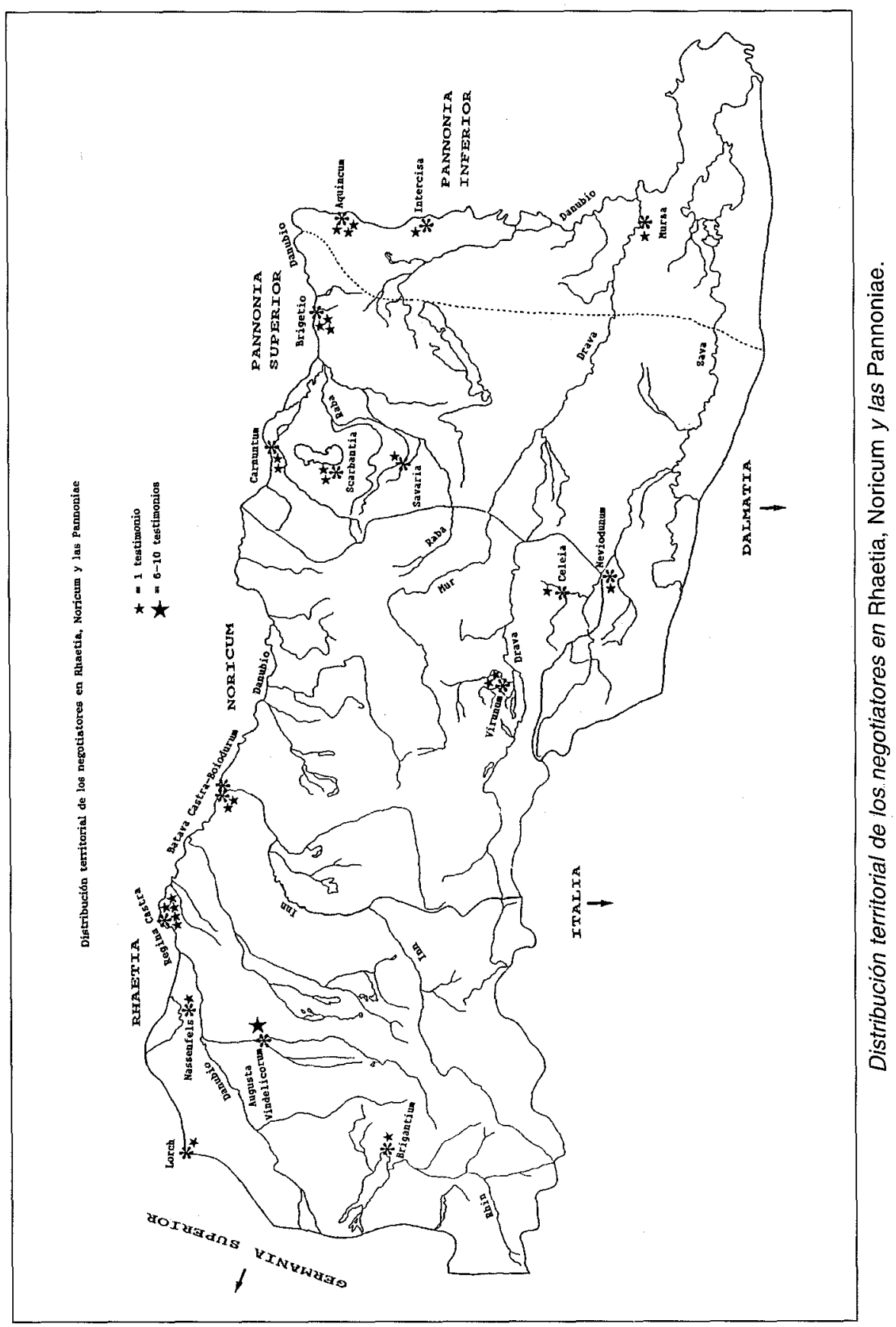

